\title{
Climatologia aplicada na análise de desastres urbanos: o caso do evento climático de Bodocó, Pernambuco, Brasil
}

Climatology applied in the analysis of urban disasters: the case of the climatic event of Bodocó, Pernambuco, Brazil

Climatología aplicada en el análisis de desastres urbanos: el caso del evento climático de Bodocó, Pernambuco, Brasil

Recebido: 04/05/2020 | Revisado: 07/05/2020 | Aceito: 09/05/2020 | Publicado: 17/05/2020

Maria Fernanda da Cruz Silva

ORCID: https://orcid.org/0000-0003-3346-6678 Instituto Federal de Educação, Ciência e Tecnologia do Ceará, Brasil E-mail: fernandacsilva56@gmail.com

Eliezio Nascimento Barboza

ORCID: https://orcid.org/0000-0001-8100-9389 Instituto Federal de Educação, Ciência e Tecnologia do Ceará, Brasil

E-mail: eliezio1999@outlook.com

Ana Millene dos Santos Silva

ORCID: https://orcid.org/0000-0003-2110-8056 Instituto Federal de Educação, Ciência e Tecnologia do Ceará, Brasil E-mail: anasantosmillene@gmail.com

\section{Resumo}

O estudo do clima é uma importante ferramenta para o entendimento dos fenômenos atmosféricos que afetam diretamente a vida humana, como os extremos de precipitação, temperatura, umidade relativa do ar e os eventos climáticos, como por exemplo chuvas intensas ou os longos períodos de estiagem na região Nordeste do Brasil. Esses eventos são responsáveis por fortes impactos socioecômicos para as populações. Neste contexto, o presente trabalho aborda um estudo de caso do extremo climático ocorrido no município de Bodocó- PE em abril de 2018, onde a cidade foi inundada após fortes precipitações. Pelos bancos de dados da Agência Pernambucana de Águas e Clima, Centro de Previsão de Tempo e 
Estudos Climáticos, Centro de Hidrografia da Marinha do Brasil e o Instituto Brasileiro de Geografia e Estatística foi possível realizar a análise meteorológica e estatística do evento, usando software Excel para cálculos de estatística descritiva por meio dos parâmetros: média histórica, mediana, desvio padrão (DP), variância, valor mínimo e máximo, amplitude e coeficiente de variação das precipitações pluviométricas acumuladas no mês de abril em 2018. Os resultados obtidos demonstram a irregularidade e mal distribuição das chuvas no período em análise, as previsões de notificadas de instabilidade para a região nos dias 05 e 13 de abril em 2018, bem como os impactos causados para a população onde cerca de 817 pessoas ficaram desabrigadas.

Palavras-chave: Meteorologia; Precipitação pluviométrica; Sertão pernambucano.

\section{Abstract}

The study of climate is an important tool for understanding atmospheric phenomena that directly affect human life, such as the extremes of precipitation, temperature, relative humidity and climatic events, such as intense rains or long periods of drought in the Northeast region of Brazil. These events are responsible for strong socio-economic impacts on populations. In this context, the present work addresses a case study of the extreme climatic occurred in the municipality of Bodocó-PE in April 2018, where the city was flooded after heavy rainfall. Through the databases of the Pernambuco Water and Climate Agency, The Center for Weather Forecasting and Climate Studies, the Hydrography Center of the Brazilian Navy and the Brazilian Institute of Geography and Statistics, it was possible to perform the meteorological and statistical analysis of the event, using Excel software for descriptive statistical calculations through the following parameters: historical mean, median, standard deviation (SD), variance, minimum and maximum value, amplitude and coefficient of variation of rainfall accumulated in April 2018. The results obtained demonstrate the irregularity and poor distribution of rainfall in the period under analysis, the forecasts of instability for the region on April 5 and 13 in 2018, as well as the impacts caused to the population where about 817 people were left homeless.

Keywords: Meteorology; Rainfall; Sertão Pernambucano.

\section{Resumen}

El estudio del clima es una herramienta importante para entender los fenómenos atmosféricos que afectan directamente a la vida humana, como los extremos de las precipitaciones, la temperatura, la humedad relativa y los eventos climáticos, como lluvias intensas o largos 
períodos de sequía en la región noreste de Brasil. Estos eventos son responsables de fuertes impactos socioeconómicos en las poblaciones. En este contexto, el presente trabajo aborda un estudio de caso sobre las condiciones climáticas extremas ocurridas en el municipio de Bodocó- PE en abril de 2018, donde la ciudad se inundó tras fuertes lluvias. A través de las bases de datos de la Agencia de Agua y Clima de Pernambuco, el Centro de Previsión Meteorológica y Estudios Climáticos, el Centro Hidrográfico de la Marina de Brasil y el Instituto Brasileño de Geografía y Estadística, fue posible realizar el análisis meteorológico y estadístico del evento, utilizando el software Excel para cálculos estadísticos descriptivos a través de los siguientes parámetros: media histórica, mediana, desviación estándar (SD) , varianza, valor mínimo y máximo, amplitud y coeficiente de variación de las precipitaciones acumulada en abril de 2018. Los resultados obtenidos demuestran la irregularidad y la mala distribución de las precipitaciones en el período objeto de análisis, las previsiones de inestabilidad para la región los días 5 y 13 de abril de 2018, así como los impactos causados a la población donde unas 817 personas se quedaron sin hogar.

Palabras clave: Meteorología; Lluvias; Serto Pernambucano.

\section{Introdução}

O estudo do clima é um dos interesses da humanidade desde as primeiras civilizações. Com o entendimento dos fenômenos atmosféricos, as populações alcançaram a compreensão dos fenômenos e a manipulá-los (Mendonça \& Oliveira, 2007). Historicamente as atividades humanas recebem influências decorrente das variabilidades climáticas, como variações pluviais, de temperatura e constância de eventos extremos, caso por exemplo das chuvas intensas e secas severas. Extremos climáticos resultam em impactos nos recursos hídricos, agricultura, saúde e meio ambiente (Souza, Azevedo \& Araújo, 2012).

Dentre os fenômenos climáticos podemos citar aqueles que aumentam consideravelmente as precipitações pluviométricas em algumas regiões e diminuem em outras, como os fenômenos El Nino e La Nina (Barboza, Caiana \& Bezerra Neto, 2020). A precipitação pluviométrica refere-se à água derivada da condensação do vapor d'água da atmosfera, depositada na superfície terrestre sob a forma de chuva (Tundisi, 2003). Ometto (1981) afirma que a chuva possui uma distribuição regular relativo ao seu quantitativo, porém elas não são proporcionais no decorrer do seu ciclo anual.

Para Souza, Azevedo \& Araújo (2012) a precipitação é uma das variáveis meteorológicas mais relevantes para estudos climatológicos, resultante da sua influência nos 
diversos setores sociais, pois as chuvas intensas podem originar enchentes, alagamentos, desastres e acidentes em áreas ocupadas e principalmente em aglomerados urbanos e rurais. De acordo com Kobiyama et al. (2006) esses acontecimentos são decorrentes do esforço humano em tentar controlar a natureza, na qual na maioria das vezes é vencido pelos desastres hidro meteorológicos. Castro (2003) entende como desastres hidro meteorológicos aqueles causados por chuvas prolongadas (inundações graduais ou enchentes) e aqueles causados por chuvas concentradas (enxurradas ou inundações bruscas e alagamentos).

O número de ocorrências relacionadas a desastres ambientais aumentou consideravelmente nas últimas décadas em diversas regiões do globo (Souza, Azevedo, Assis \& Sobral, 2014). Esse aumento se deve ao crescente aumento populacional, o forte processo de industrialização, urbanização e a ocupação populacional desordenada, sendo intensificado nas áreas urbanas pela impermeabilização do solo, a poluição do ar, a conservação de calor e o adensamento urbano (Kobiyama et al., 2006).

As inundações causadas por chuvas violentas nas áreas urbanas são os impactos mais comuns oriundos de eventos climáticos (Arnbjerg-Nielsen et al., 2013). Esses intensos eventos são caracterizados como aqueles que em seus totais, sejam eles sazonais, anuais ou diário, em um período examinado, apresentam desvios da sua conduta rotineira, podendo ser inferior ou superior (Souza, Azevedo, Assis \& Sobral, 2014). O estudo da precipitação pluviométrica no âmbito da climatologia através da análise dos impactos e frequência de eventos extremos é essencial para que seus efeitos sejam minimizados (Kobiyama et al., 2006; Steinke, Rezende \& Cavalcanti, 2006; Medeiros, 2013; Monteiro \& Kobiyama, 2014; Duarte, Nóbrega \& Coutinho, 2015; Barboza, Caiana \& Bezerra Neto, 2020).

Extremos climáticos, como secas severas ou enchentes, alteram significativamente as características de uma determinada localidade, gerando problemáticas para população, seja nos grandes centros urbanos com inundações, como também estiagens prolongadas no sertão (Nóbrega, Farias \& Santos, 2015). Chuvas intensas em cidades nordestinas podem danificar os sistemas sanitários, já os longos períodos de seca causam grandes prejuízos agrícolas nessas regiões (Becker, Melo \& Costa, 2013).

Moura, Cunico, Nóbrega \& Duarte (2016) em um estudo sobre a Região Nordeste do Brasil, apresentaram uma análise das ocorrências dos desastres naturais, relativos à ordem hidrológica e meteorológica por estados e municípios da região, apresentando que o Nordeste do país possui o maior número de desastres naturais reconhecidos por decretos de Estado de Calamidade Pública no país. Castellano \& Nunes (2014) ao analisar as chuvas intensas e suas consequências nos Municípios de Itatiba e Valinhos, verificaram os dias que houve chuvas 
extremas e observaram também os impactos mais frequentes no período de 1970 a 2010, mostrando que as consequências mais trágicas correspondem a pessoas desabrigadas, e inclusive a mortalidade.

Nesse contexto, o presente estudo busca determinar as precipitações, como também avaliar os impactos decorrentes dos eventos extremos no sertão nordestino, mais especificamente no município de Bodocó, Pernambuco. Importante considerar que a cidade não enfrentava enchentes nessa proporção há mais de 60 anos. O evento climático de interesse nesse estudo aconteceu em abril de 2018.

\section{Metodologia}

\subsection{Tipo de pesquisa}

Conforme caracterizam Pereira, Shitsuka, Parreira \& Shitsuka (2018) do ponto de vista da natureza, esse trabalho trata de uma pesquisa básica. Pela perspectiva de abordagem, é uma pesquisa qualitativa. Analisando os objetivos essa pesquisa é exploratória. Em relação aos procedimentos técnicos é do tipo estudo de caso.

\subsection{Descrição da área de estudo}

O presente trabalho envolve o município de Bodocó-PE (Figura 1), situado no semiárido pernambucano. A história do semiárido nordestino está profundamente relacionada com secas severas ou grandes enchentes, impactando no aumento da fome, pobreza e consequentemente no desemprego e êxodo rural, isso acontece devido à irregularidade das chuvas, no qual afeta o desenvolvimento das atividades agrárias, agropecuárias, e condições de vida da população (Marengo, Alves, Beserra \& Lacerda, 2011).

O Município de Bodocó possui as seguintes coordenadas geográficas 07 46' 42" Sul de Latitude (S) e Longitude (W) de 39 56' 28". A altitude média da Região é de 440 metros, localiza-se na mesorregião Sertão e na Microrregião Araripina do Estado de Pernambuco, com área aproximada de $1.605 \mathrm{~km}^{2}$ e uma população de 38.146 habitantes (IBGE, 2019). A Figura 1 apresenta a localização geográfica da área de estudo em relação ao Estado de Pernambuco e ao país. 
(CC BY 4.0) | ISSN 2525-3409 | DOI: http://dx.doi.org/10.33448/rsd-v9i7.4227

Figura 1: Localização do município de Bodocó e cidades limítrofes de Pernambuco.
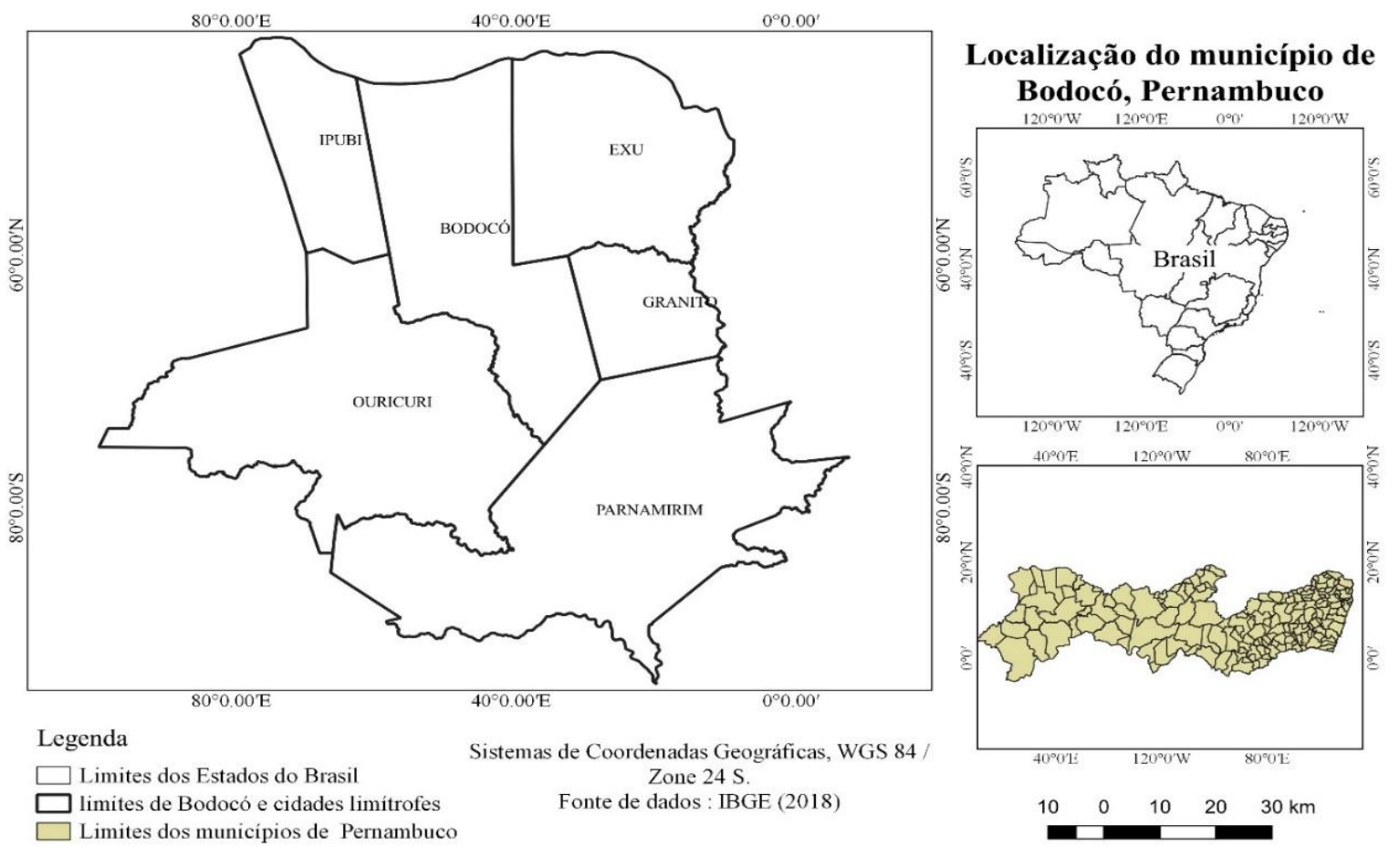

Fonte: Autores, 2020. Elaborado no software Qgis 4.3.

Pela Figura 1, verifica-se as cidades e Estados limítrofes: Ipubi, Ouricuri, Parnamirim, Exu e Granito. De acordo com a classificação de Köppen, o tipo climático da região é BSh, clima tropical quente semiárido quente e semiárido (Bacalhau, Neto \& Oliveira, 2017). O município está inserido na região fisiográfica do sertão nordestino, caracterizado pela insuficiência das chuvas, com altas temperaturas e evaporação (Nobre \& Melo, 2001).

O Bioma típico da área de estudo é Caatinga, o clima da região é caracterizado pela dupla estacionalidade, possuindo um período chuvoso e outro seco (Sá, Galvincio, Moura \& Sá, 2010). O Município de Bodocó está inserido na unidade geoambiental das Chapadas Altas com altitude superior a 800 metros, exibindo encostas íngremes e vales abertos (MME, 2005).

Bodocó-PE encontra-se inserido nos domínios da Bacia Hidrográfica do Rio da Brígida, com os principais riachos: Sipauba, do Olho d'Água, Tucano, Santo Antônio, Pombal, Gravatá, do Mel, do Camaleão, do Aço, da Volta, Umburana, do Ferreiro, do Manoino, do Algodão, do Lopes, do Caracui, das Letras, Cacimbas, da Garça ou Logradouro e da Selada, com todos os corpos aquáticos de regime de escoamento intermitente (MME, 2005). 
Research, Society and Development, v. 9, n. 7, e375974227, 2020

(CC BY 4.0) | ISSN 2525-3409 | DOI: http://dx.doi.org/10.33448/rsd-v9i7.4227

Através da Figura 2, é possível identificar as feições topográficas de altitude mais representativas do Município de Bodocó - PE, corroborando para a compreensão das características ambientais da área de estudo, variando de 393 a 920 metros.

Figura 2: Hipsometria do município de Bodocó, Pernambuco.

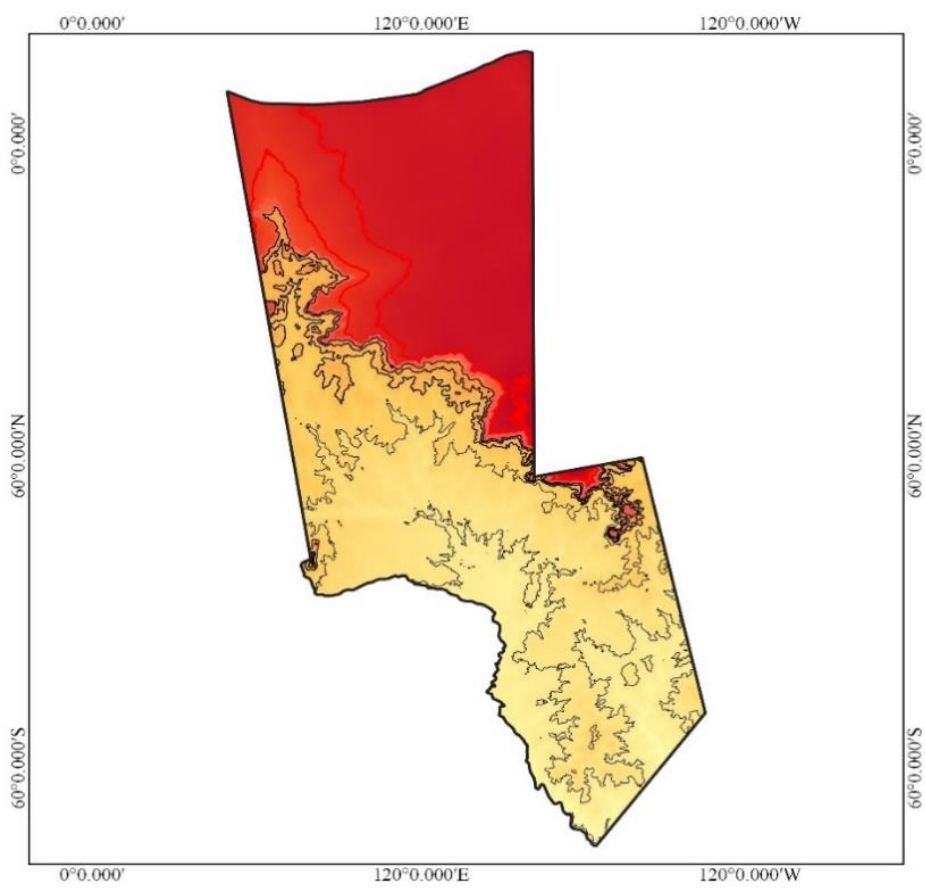

Hipsometria e curvas de nível do município de Bodocó, Pernambuco

Legenda

Hipsometria

$\square$ Limites do municipio de Bodocó

Curvas de nivel

- 400,0000 - 525,0000

$-525,0000-650,0000$

- $650,0000-775,0000$

$-775,0000-900,0000$

Altitude $(m)$

$\square 393$

$\square 25$

- 656

788
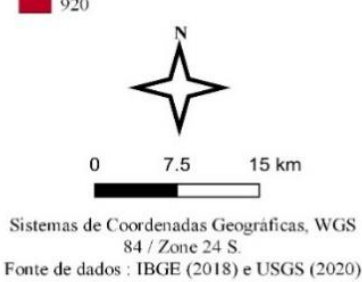

Fonte: Autores, 2020. Elaborado no software Qgis 4.3.

Na Figura 2 as altitudes são representadas por diferentes cores através de um sistema de graduação de cores não aleatórias. Barboza, Bezerra Neto \& Caiana (2020) afirmam que geralmente as cores mais escuras (vermelho escuro, vermelho claro e laranja) representam as maiores altitudes, as cores mais claras (branco e laranja claro) representam médias e baixas altitudes.

\subsection{Procedimentos metodológicos}

Realizou-se um levantamento bibliográfico sobre as anomalias de precipitações na região do Sertão pernambucano no mês de abril de 2018, analisando as causas e consequências dessas anomalias atmosféricas especificamente no município de Bodocó - PE, campo de estudo delimitado para análise de evento climático.

Os dados foram obtidos a partir de sites especializados no contexto, especialmente nos portais da Agência Pernambucana de Águas e Clima - APAC (2018), Centro de Previsão de 
(CC BY 4.0) | ISSN 2525-3409 | DOI: http://dx.doi.org/10.33448/rsd-v9i7.4227

Tempo e Estudos Climáticos - CPTEC/INPE (2018), Centro de Hidrografia da Marinha do Brasil (2018) e o Instituto Brasileiro de Geografia e Estatística - IBGE (2018).

Relativo aos impactos causados na cidade, os dados foram obtidos a partir de jornais e/ou sites de notícias regionais e/ou locais. Partindo dos dados coletados, a análise foi delimitada ao mês de abril, buscando identificar nas estatísticas e nos estudos meteorológicos, os motivos pelos quais ocorreu a maior precipitação de 2018.

\section{Resultados e Discussão}

A partir da análise dos resultados, constata-se através do Gráfico 1, que há discrepância dos valores precipitação total acumulada para o mês de abril no período analisado (1981- 2019).

Gráfico 1: Precipitações pluviométricas acumuladas para o mês de abril em Bodocó, PE.

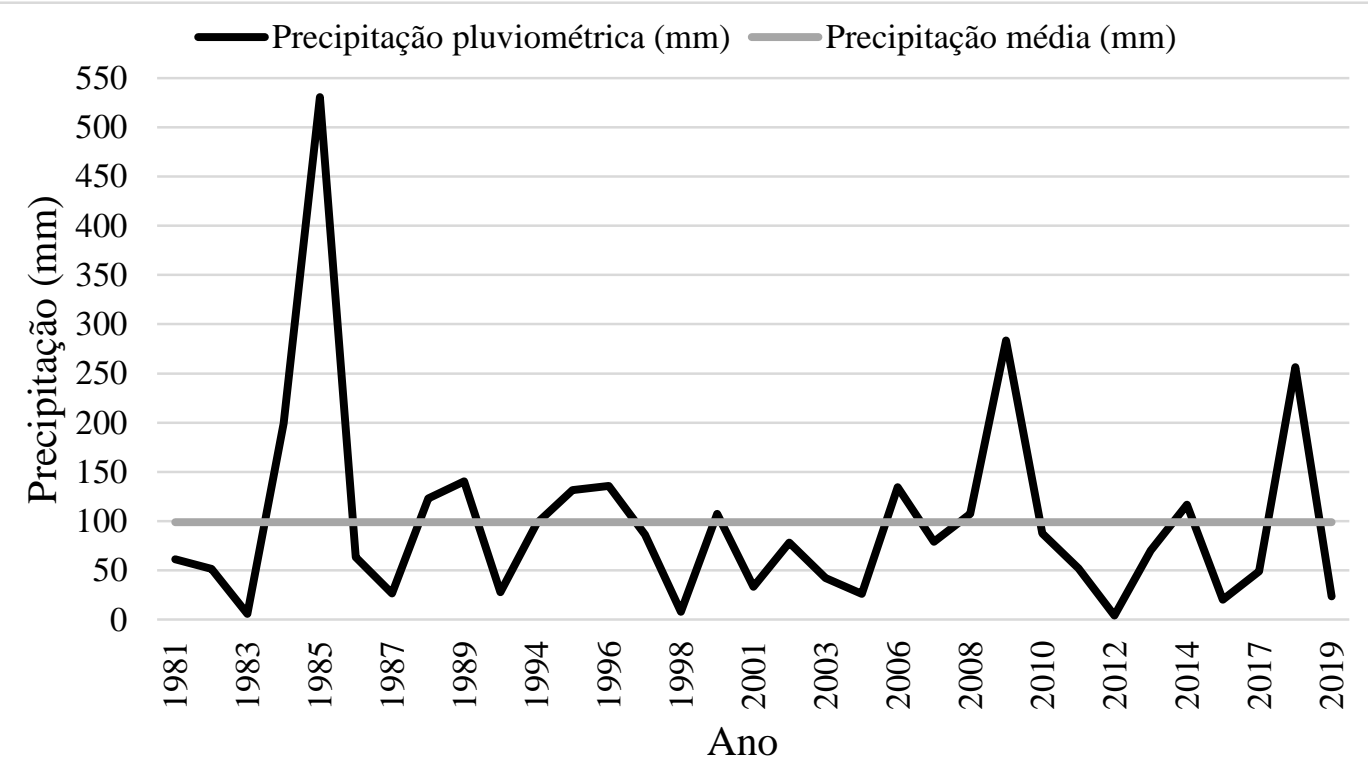

Fonte: Autores, 2020. Elaborado no software Excel.

Pela análise do Gráfico 1 verifica-se os anos com maiores precipitações pluviométricas para o mês de abril, destaca-se os anos 1985, 2009 e 2018, com valores superiores à média de precipitação. Nota-se que a média dos valores de precipitações para o mês de abril é 98.79 mm no intervalo de estudo (1981-2019), sendo possível identificar anomalias através da exposição dos anos que apresentaram precipitações pluviométricas superiores e inferiores à média referente ao período em estudo. 
O ano com maior índice pluviométrico para o mês de abril foi em 1985 com 530.5 mm, em seguida o ano de 2009 com 283.4 mm e 2018 com $256.5 \mathrm{~mm}$. Segundo Molion \& Bernardo (2002) as anomalias pluviométricas estão relacionadas com a atuação dos sistemas atmosféricos da Zona de Convergência Intertropical (ZCIT), os sistemas Frontais (SF), distúrbio Ondulatórios de Leste (DOLS) e os vórtices Ciclônicos de Altos Níveis (VCAN), a razão dessas anomalias pluviométricas pode ter sido motivada pelo transporte de umidade relativa do ar do Atlântico tropical e da bacia Amazônica, como também possivelmente pela atuação do El Nino e La Nina. Pela falta de dados para os anos de 1990, 1991, 1992, 1999, 2004 e 2016, esses anos não foram contabilizados nesse estudo, possivelmente por erros nos pluviômetros da Agência Pernambucana de Águas e Clima - APAC.

A Tabela 1 apresenta os parâmetros estatísticos das precipitações pluviométricas acumuladas para o mês de abril.

Tabela 1: Estatística descritiva da série precipitações pluviométricas acumuladas para o mês de abril no período (1981-2019).

\begin{tabular}{cc}
\hline Estatística descritiva da precipitação - abril (1981 - 2019). \\
Média & 98.79 \\
Desvio Padrão & 102.19 \\
Variância & 10442.49 \\
Valor mínimo & 4.00 \\
Valor máximo & 530.50 \\
Amplitude & 526.50 \\
Coeficiente de variação (CV) & 1.03 \\
Assimetria & 2.70 \\
Curtose & 9.51
\end{tabular}

Fonte: Autores, 2020. Elaborado no software Excel.

Verifica-se na Tabela 1, o valor de desvio padrão para o mês de abril do período de 1980 a 2019 bastante elevado, provando a alta variação das chuvas no mês de abril durante o período em estudo, quando comparado com a média do mesmo. Para tanto, é evidente a irregularidade no regime de precipitação, com valor de $102.19 \mathrm{~mm}$, indicando que as chuvas históricas no mês de abril se distanciaram da média.

Nota-se pelo coeficiente de assimetria (Tabela 1), que a distribuição é assimétrica a direita, pois o valor é positivo, indicando que esse lado é maior. Corroborando com estudos de 
(CC BY 4.0) | ISSN 2525-3409 | DOI: http://dx.doi.org/10.33448/rsd-v9i7.4227

Hundecha, Pahlow e Schumann (2009), no qual afirmam que a precipitação pluviométrica comumente se apresenta como assimétrica, geralmente são modelados por famílias de distribuições que são assimétricas à direita. A precipitação mínima e máximo acumulada foi de $4 \mathrm{~mm}$ e $530.5 \mathrm{~mm}$, respectivamente. Através da diferença entre o valor máximo e mínimo, caracteriza a amplitude, com valor de $526.5 \mathrm{~mm}$.

O Gráfico 2 apresenta a precipitação pluviométrica diária para o mês de abril de 2018, mês do evento climático em estudo.

Gráfico 2: Precipitações pluviométricas diárias acumuladas para 04/2018 em Bodocó, PE.

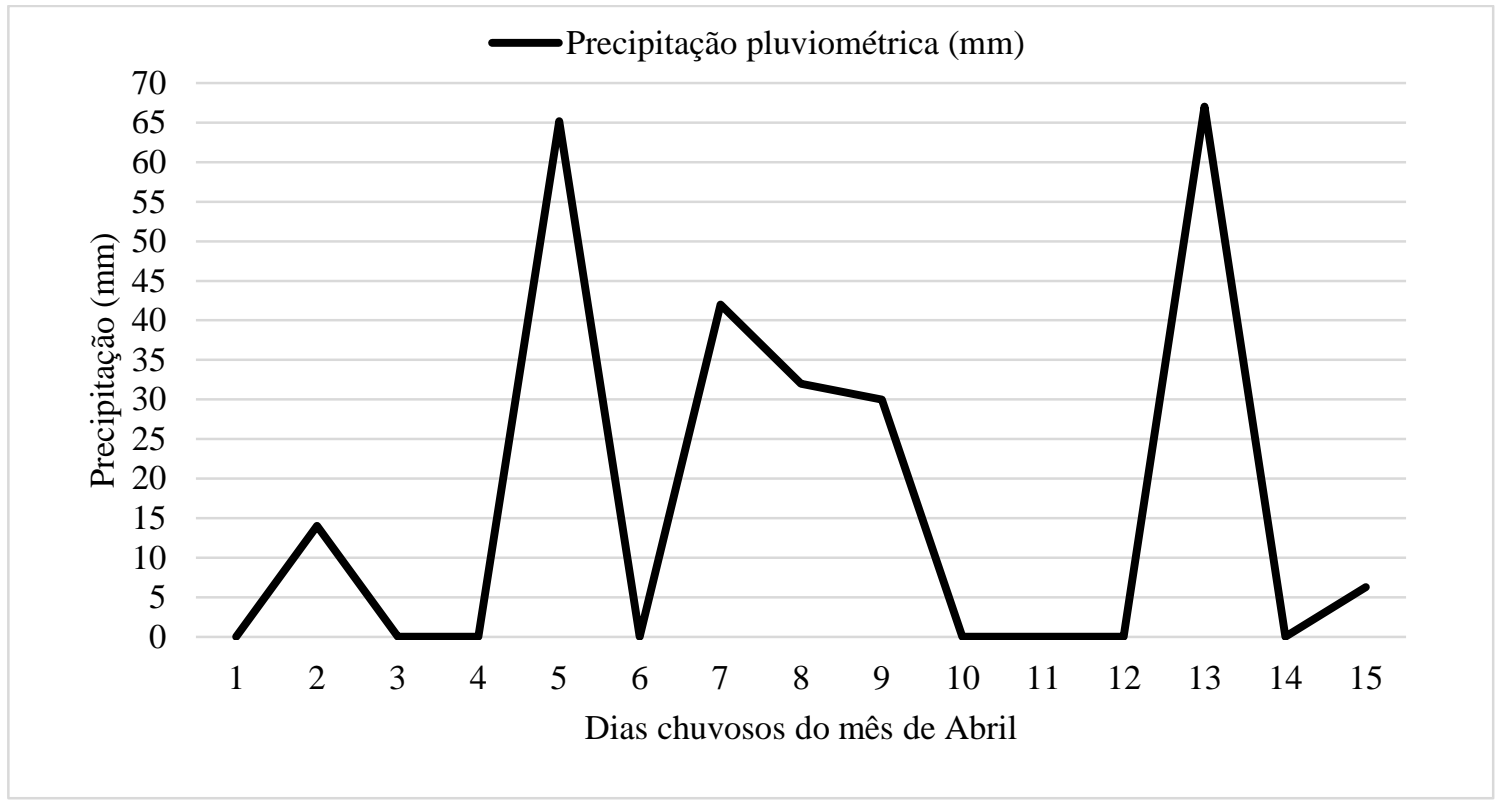

Fonte: Autores, 2020. Elaborado no software Excel.

Pela análise do Gráfico 2, nota-se que as chuvas foram concentradas em poucos dias do mês, especialmente nos dias 5 e 13, com 65 e 67 mm, respectivamente. Após o dia 15 não houve registros de precipitação, portanto a pluviometria é igual a $0 \mathrm{~mm}$. Brandão e Hipólito (1995) complementa ao afirmar que o regime pluviométrico é oscilatório, podendo ocorrer períodos chuvosos ou com secas severas, caracterizado pela distribuição irregular, com aproximadamente $90 \%$ das precipitações ocorrendo em curto espaço de tempo. Provocando problemas sociais, econômicos e ambientais por enchentes ou estiagens. No caso de Bodocó $\mathrm{PE}$, as precipitações intensas no curto espaço de tempo, intensificada pela ineficácia da estrutura urbana, especialmente pela falta de drenagem urbana, provocaram transtornos para o município. 
Research, Society and Development, v. 9, n. 7, e375974227, 2020

(CC BY 4.0) | ISSN 2525-3409 | DOI: http://dx.doi.org/10.33448/rsd-v9i7.4227

A Tabela 2 apresenta os parâmetros estatísticos para as precipitações pluviométricas acumuladas para o mês de abril de 2018. O mês de abril integra o final da quadra de chuvas no Sertão Pernambucano, outrossim a precipitação nessa região foi de $31 \%$ acima da média histórica climatológica para o período, caracterizando a anomalia em estudo.

Tabela 2: Estatística descritiva da série precipitações pluviométricas acumuladas para o mês de abril de 2018.

\begin{tabular}{cc}
\hline \multicolumn{2}{c}{ Estatística Descritiva mensal - abril/2018 } \\
\hline Precipitação acumulada (mm) & 256.5 \\
Média & 8.55 \\
Mediana & 0 \\
Desvio Padrão (DP) & 18.68 \\
Coeficiente de variação & 2.185 \\
Valor máximo & 67 \\
Valor mínimo & 0 \\
Variância & 349.02 \\
Amplitude & 67 \\
Percentual do acumulado em relação à média & $241 \%$
\end{tabular}

Fonte: Autores, 2020. Elaborado no software Excel.

A Tabela 2 apresenta os parâmetros estatísticos, como: média, mediana, desvio padrão, coeficiente de variação, valor máximo, valor mínimo, variância e amplitude dos valores de precipitação para o período estudado. Relativo ao desvio padrão do município o valor foi de 18,68 mm, indicando que houve um alto grau de oscilação em comparação com a média que é de $8,55 \mathrm{~mm}$.

O desvio padrão indica o grau de dispersão de dados, relativo à uniformidade, desta maneira quanto mais próximo de zero, mais homogêneo são os dados, ou seja, menor a discrepância quando relacionado com a média. O coeficiente de variação $(\mathrm{CV})$ fornece uma variação dos dados em relação à média, o valor obtido foi de 218,50\%, um valor alto, uma vez que o CV é considerado baixo quando obtêm-se valores menores ou iguais a $25 \%$, evidenciando que as chuvas foram mal distribuídas ao longo do mês.

Verifica-se, nos dados, a característica de uma alta variabilidade pluviométrica, quando comparados com a média, em que existem dias com índices bastante elevados e outros com valores tão baixos que chegam a zero. Olímpio (2013) relata que as cidades do 
(CC BY 4.0) | ISSN 2525-3409 | DOI: http://dx.doi.org/10.33448/rsd-v9i7.4227

semiárido, nas quais prevalece um clima seco e quente, os episódios de chuvas extremas acontecem com uma certa periodicidade.

Verifica-se pelo Gráfico 2 e a Tabela 2 que houve uma oscilação significativa dos valores médios de precipitação diária no período de estudo no município de Bodocó, no qual a cidade apresentou chuvas com acúmulo mensal de $256,5 \mathrm{~mm}$ referente ao mês de abril, com valores acima da média histórica de precipitação. Deste modo, houve um percentual do acumulado em relação à média de $241 \%$, apresentando um desvio no valor de $141 \%$ acima do esperado para o mês.

Na Figura 3, o Boletim Técnico da CPTEC para o dia 13 de abril de 2018 mostrou que estava previsto uma instabilidade para o Nordeste do Brasil, com previsões de chuvas na região. As linhas vermelhas de espessura geopotencial em Pernambuco indicam que a massa de ar quente tende a subir, formando nuvens e provocando uma maior probabilidade de precipitação para esse dia.

Figura 3: Imagem de superfície - Boletim Técnico para 13/04/2018.

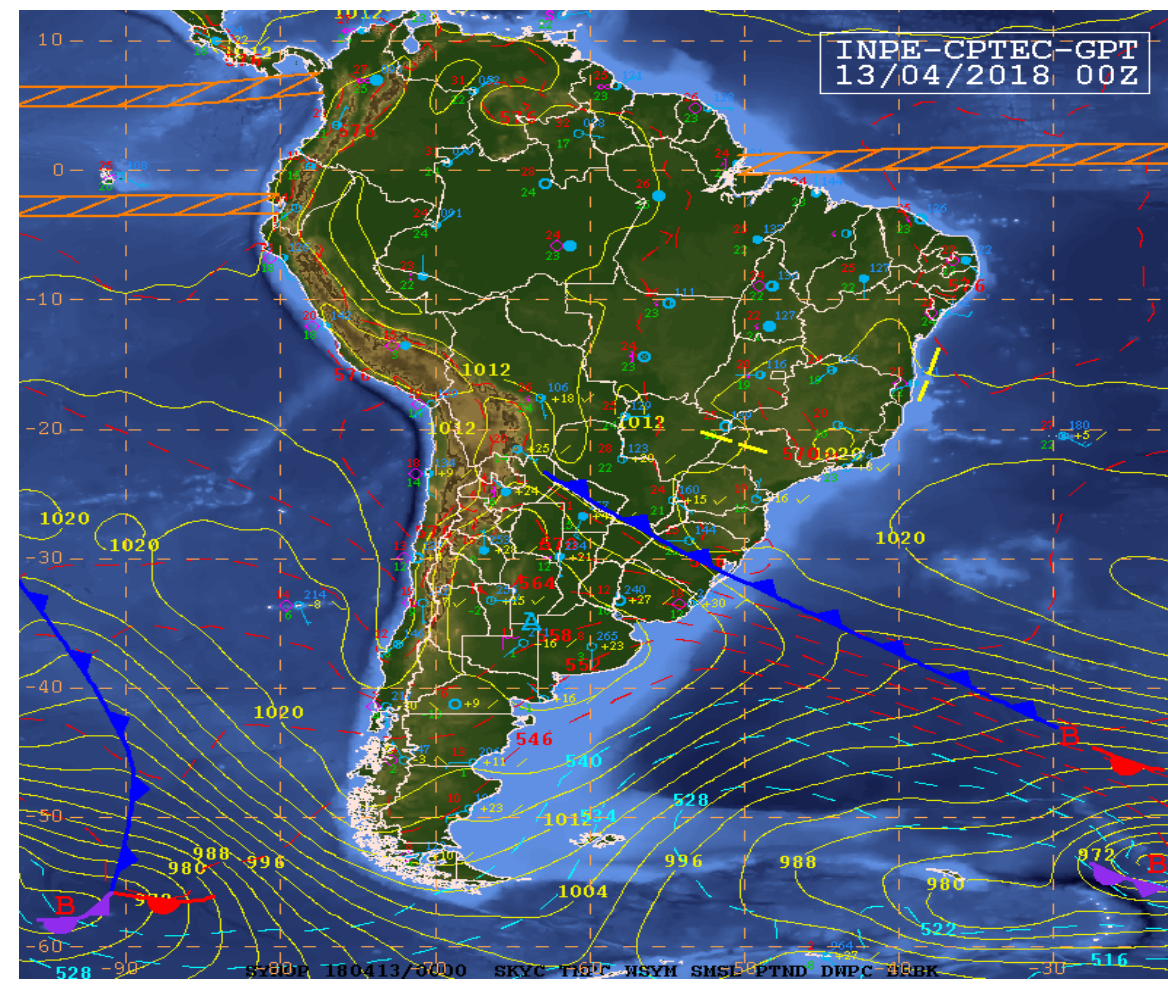

Fonte: CPTEC/INPE, 2018.

No Nordeste, especialmente no Pernambuco houve uma grande instabilidade climática em abril devido à influência da Zona de Convergência Intertropical - ZCIT, sistema meteorológico que influencia nas chuvas pela transferência de calor e umidade do oceano para 
(CC BY 4.0) | ISSN 2525-3409 | DOI: http://dx.doi.org/10.33448/rsd-v9i7.4227

os níveis mais altos da troposfera. Logo, esse sistema atmosférico influenciou diretamente nas chuvas de Bodocó (CPTEC, 2018).

A Figura 4 apresenta a predominância de um Cavado de Altos Níveis no Nordeste, com eixo centrado no litoral nordestino, sucedendo em uma posição favorável a formação chuvas ocorridas no Estado pernambucano.

Figura 4: Linhas de correntes em 200 hPa referente ao mês de abril de 2018.

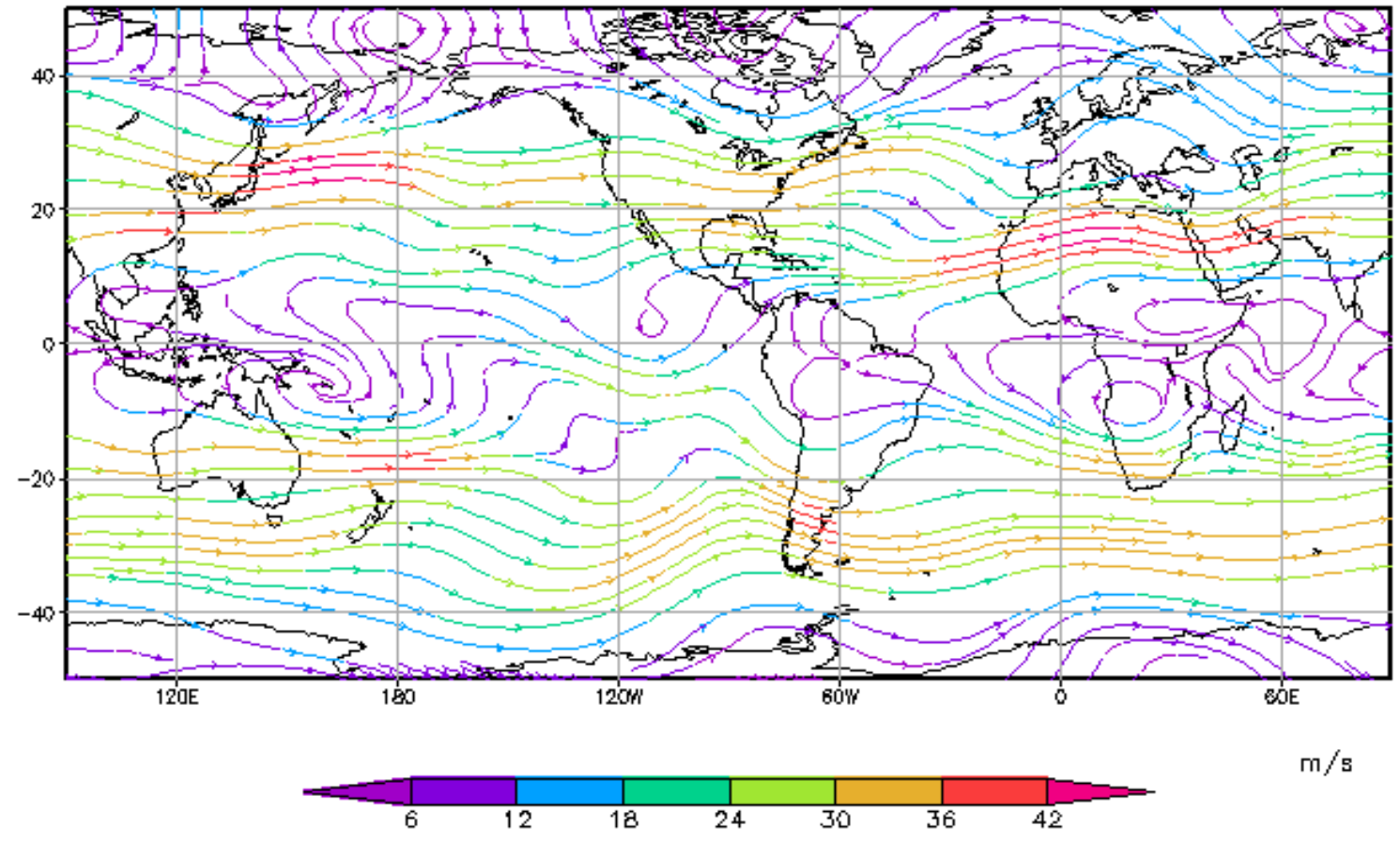

Fonte: CPTEC/INPE, 2018.

A temperatura superficial (TSM) no mar do Atlântico permaneceu em volta do normal na região equatorial (APAC, 2018), mas mesmo assim sucedeu precipitações significativas, gerando acúmulo pluviométrico acima da climatologia. De acordo com a APAC (2018) os distúrbios ondulatórios de leste (DOL) e os distúrbios da Zona de Convergência Intertropical (ZCIT) sucederam as precipitações acima da normalidade. As chuvas ocorridas no mês de abril contribuíram para a diminuição da intensidade e das áreas de seca em todo o estado do Pernambuco. Em relação ao sertão passou-se a ter uma diminuição de sua intensidade, locais onde variavam de secas graves a excepcionais, passaram a apresentar-se como secas variando de moderada a leve.

A Figura 5 mostra o boletim pluviométrico da APAC para 04 de abril, dia anterior a uma das maiores precipitações nesse mês. 
Figura 5: Boletim Pluviométrico diário, 04/04/2018.

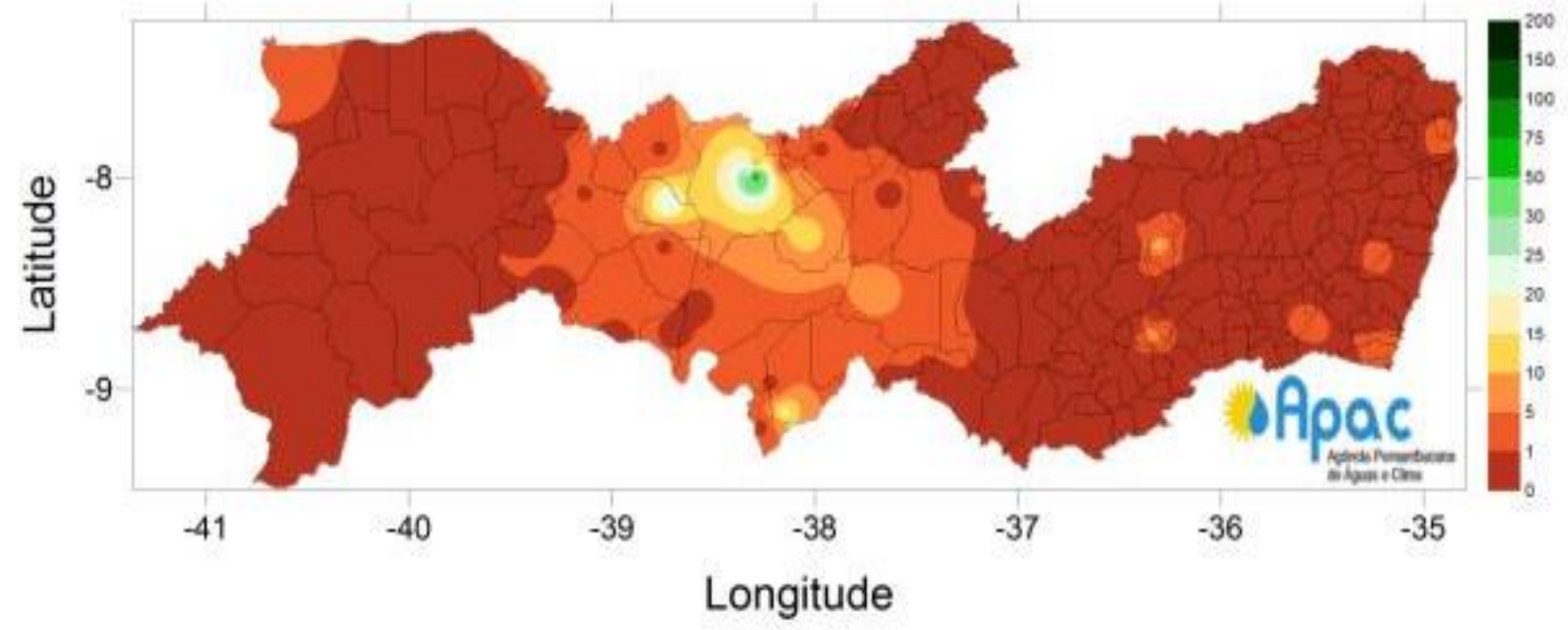

Fonte: APAC, 2018.

Pela análise da Figura 5, verifica-se que não há registro de chuvas na maior parte do Estado de Pernambuco, com exceção do município de Serra Talhada com 62,5 mm. A Figura 6 apresenta o boletim de chuvas para o dia 05 de abril, um dos dias de maior precipitação em Bodocó.

Figura 6: Boletim Pluviométrico diário, 05/04/2018.

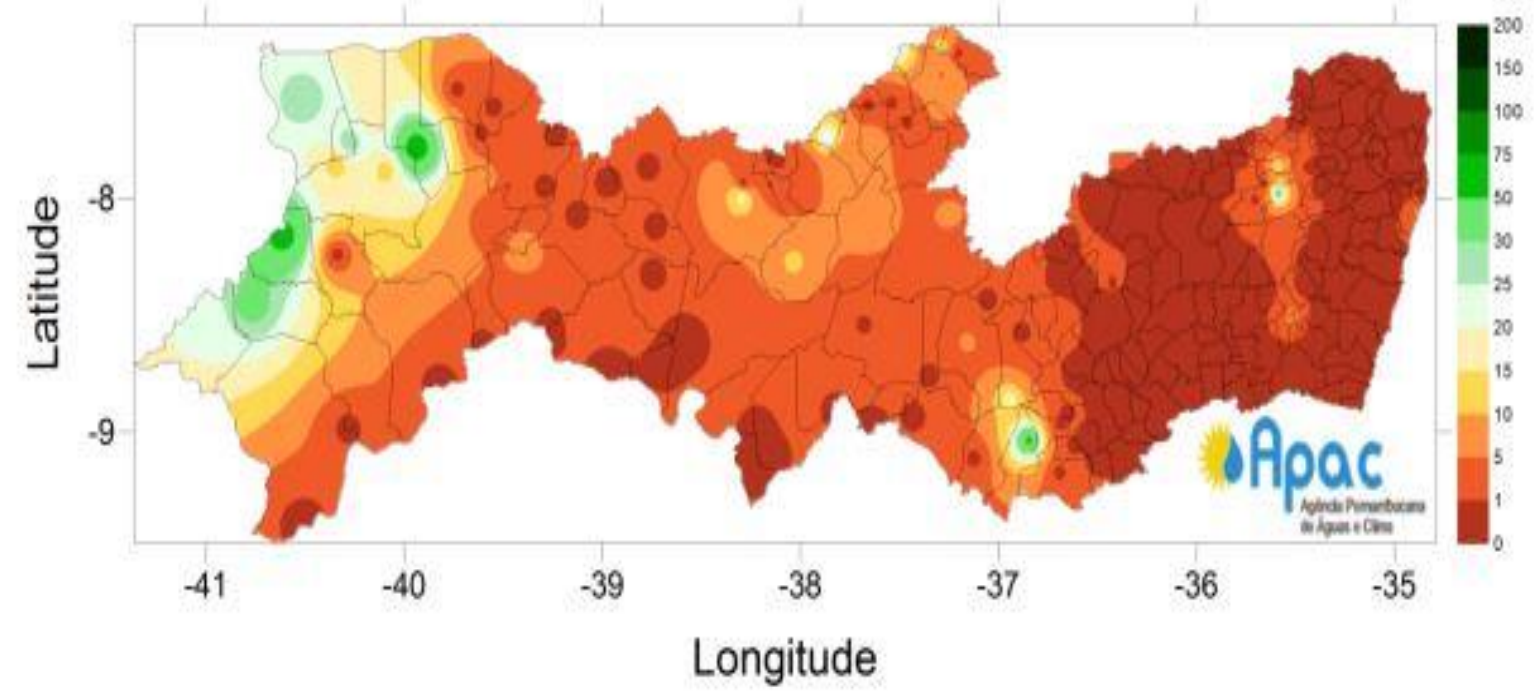

Fonte: APAC, 2018.

Pela análise da Figura 6, percebe-se que as maiores concentrações de precipitação no dia 5 foram registradas no município de Bodocó, com 65,2 mm. Na Figura 7 é mostrada a 
precipitação acumulada para o dia 12 de abril, que também antecede um dos dias de maiores chuvas para Bodocó.

Figura 7: Boletim Pluviométrico Diário, 12/04/2018.

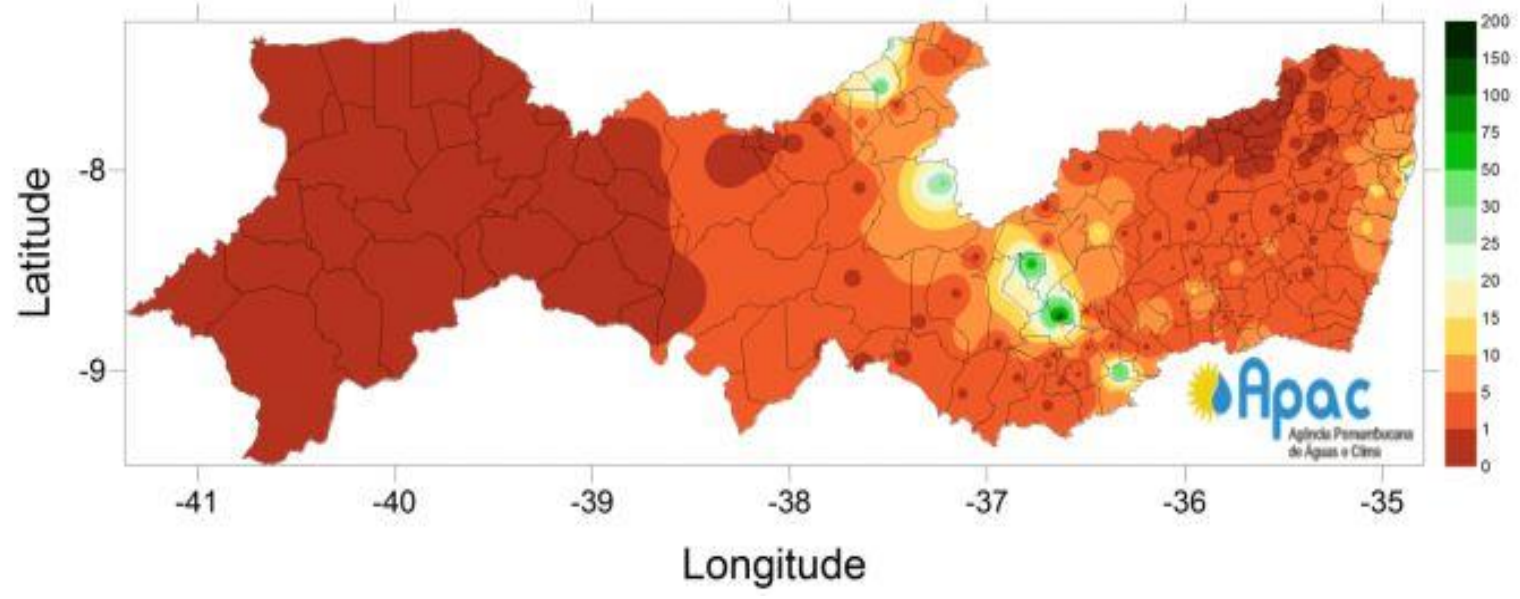

Fonte: APAC, 2018.

Analisando a Figura 7, é visível que não há registros de chuvas em Bodocó no dia 12. As maiores concentrações para essa data encontram-se no município de capoeiras com 127,3 mm. Na Figura 8 nota-se a precipitação para o dia 13 de abril, com fortes chuvas em Bodocó, embora o dia anterior tendo concentrações igual a $0 \mathrm{~mm}$.

Figura 8: Boletim Pluviométrico Diário, 13/04/2018.

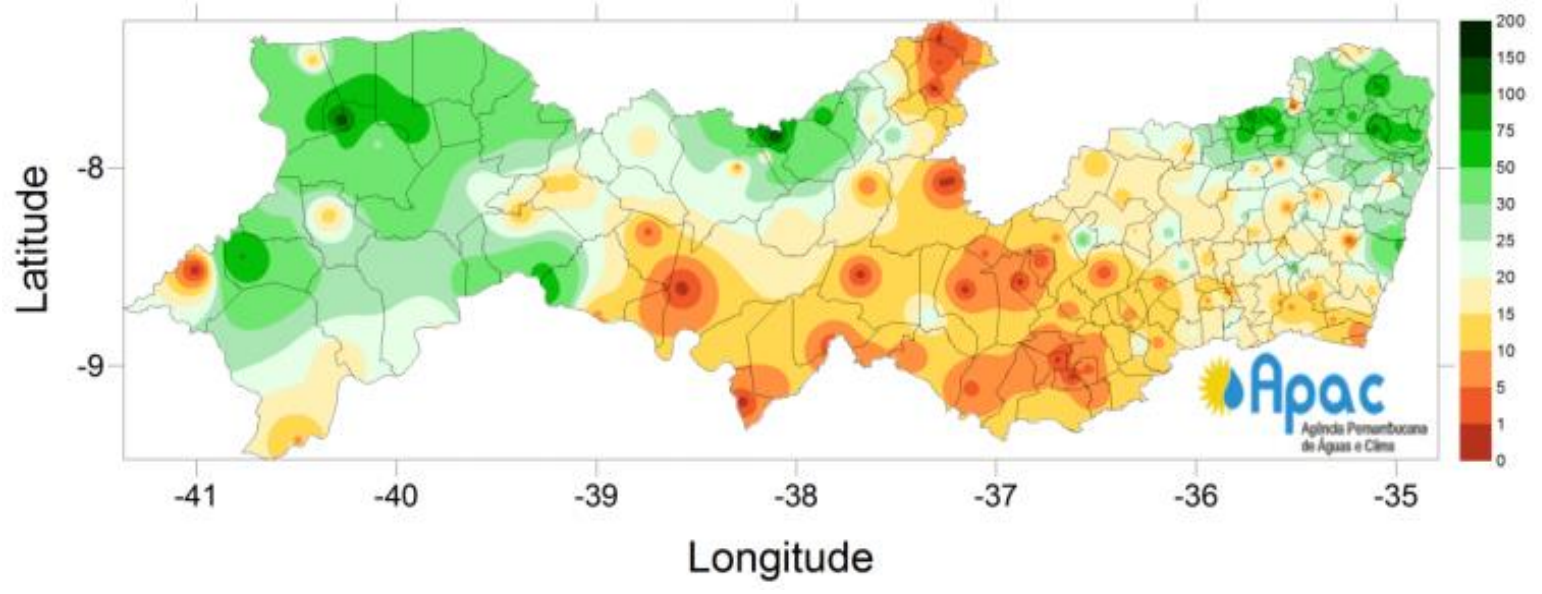

Fonte: APAC, 2018.

Analisando a Figura 8, verifica-se registros de chuvas em quase todo o Estado de Pernambuco, sendo notificados $67 \mathrm{~mm}$ em Bodocó. Neste contexto, fica claro a ocorrência de 
um evento climático no município no mês de abril em 2018. Em relação aos impactos causado na cidade devido as intensas chuvas, a Prefeitura Municipal de Bodocó decretou Estado de Situação de Emergência na Zona Urbana por um período de 180 dias, esse decreto foi oficialmente reconhecidos pelo Ministério da Integração Nacional, assim como instituiu o Comitê de Urgência e Solidariedade em Apoio às Vítimas da Enxurrada em Bodocó COMDUS BODOCÓ, um órgão consultivo e colegiado, com o intuito de dispor sobre discussão de diretrizes, organização, direcionamento, aconselhamento e recomendação relativo a concessão de ajuda destinada à população afetada pela ação da enxurrada.

Como consequência houve alagamento de ruas e avenidas, riachos ligados a bacia do Brígida transbordaram e a água adentrou casas e os moradores perderam móveis e eletrodomésticos, 340 famílias foram afetadas, contabilizando em média 817 pessoas desabrigadas. Além disso, a PE-545 que liga a cidade de Bodocó e Ouricuri, teve a sua estrutura comprometida, sendo bloqueada após parte da pista ceder. Conforme o parecer técnico, emitido pela Coordenadoria de Defesa Civil do Estado de Pernambuco (CODECIPE) a ponte apresentou uma classificação de R4, risco muito alto, assim como apresentou indícios de desestabilização e comprometimento de seus apoios.

A interdição do trecho causou prejuízos a população, como a falta de acesso a serviços públicos, a exemplo o Hospital Regional Fernando Bezerra que está localizado no município de Ouricuri-PE, assim como a falta de acessibilidade às Instituições de Ensino Superior. Há quase 60 anos a cidade não enfrentava uma enchente nessas proporções.

\section{Considerações Finais}

O presente artigo apresentou a aplicação prática da climatologia para análise de desastres urbanos, através do estudo de caso envolvendo o município de Bodocó-PE. Neste contexto, é visível a importância da meteorologia aliada as análises estatísticas para compreender os eventos climáticos que podem causar grandes impactos para as comunidades humanas. Caso em questão onde a cidade de Bodocó foi amplamente afetada por chuvas intensas acumuladas principalmente em 13 de abril de 2018.

Pelo disposto nos estudos estatísticos é perceptível a ocorrência de discrepâncias nos valores de precipitação pluviométrica acumulada, em relação à média histórica para o mês de abril entre os anos de 1981 a 2019, dando ênfase para as maiores concentrações observadas em 1985, 2009 e 2018. Além disso, abril de 2018 apresenta chuvas irregulares e intensas em um curto período de tempo nos dias 5 e 13 com mais de $60 \mathrm{~mm}$ e $0 \mathrm{~mm}$ após o dia 15 do 
mesmo mês. Estudos de desvio padrão, CV e assimetria colaboram demostrando elevada variação e mal distribuição das chuvas no período analisado.

No que se refere as previsões para os dias de maiores chuvas, que culminaram no alagamento da cidade, o Boletim Técnico mostra a instabilidade esperada para a região Nordeste do país na data de 13 de abril de 2018. Diante do episódio, cerca de 340 famílias foram afetadas onde aproximadamente 817 pessoas perderam seus imóveis. Além disso, parte da PE-545 foi interditada e rios transbordaram, o que levou o município ao estado de situação de emergência na zona urbana, mostrando os fortes impactos de eventos climáticos inesperados.

Recomenda-se para trabalhos futuros uma abordagem mais ampla sobre a ocorrência de fenômenos climáticos em regiões do semiárido nordestino, de modo a corroborar com o presente trabalho e os estudos aqui já citados. Podem ser estudados eventos ocorridos em outras localidades da região que vieram a causar impactos e transtorno para a população, especialmente os impactos sociais causados pelas chuvas nas cheias do canal do Rio Granjeiro, no Município de Crato, Ceará, Brasil.

\section{Referências}

APAC. (2018). Meteorologia, Boletins Climáticos, 2018. Acesso em 28 abril, em http://www.apac.pe.gov.br/meteorologia/boletins_climaticos_old.php.

Arnbjerg-Nielsen, K, Willems, P, Olsson, J, Beecham, S, Pathirana, A, Bülow Gregersen, I \& Nguyen, VTV. (2013). Impacts of climate change on rainfall extremes and urban drainage systems: a review. Water Science and Technology, 68(1), 16-28.

Bacalhau, JR, Neto, AR \& Oliveira, LMM. (2017). Aplicação de índice de vegetação no monitoramento da seca: açude Algodões no sertão pernambucano. Journal of Environmental Analysis and Progress, 2(3), 283-93.

Barboza, E, Bezerra Neto, F \& Caiana, C. (2020). Geoprocessamento aplicado na análise dos efeitos da urbanização no campo térmico em Fortaleza, Ceará. Research, Society and Development, $9(7)$. 
Barboza, E, Caiana, C \& Bezerra Neto, F. (2020). Rainfall analysis in the Central-South Region of Ceará: A study of the period (1980-2009). Research, Society and Development, 9(6), e18963304.

Becker, CT, Melo, MMMS \& Costa, MNM. (2013). Desempenho temporal de séries pluviométricas no estado da Paraíba: uma análise comparativa. In Workshop Internacional sobre Água no Semiárido Brasileiro (Vol. 1, pp. 1-5).

Brandão, C \& Hipólito, J. (1995). Análise de precipitações intensas. XI Simpósio Brasileiro de Recursos Hídricos. Recife. Brasil.

Castellano, MS \& Nunes, LH. (2014). Chuvas intensas e suas consequências em dois municípios médios brasileiros: Itatiba e Valinhos. In: VIII SLAGF - Simpósio Latinoamericano de Geografia Física e IV SIAGF - Simpósio Ibero-americano de Geografia Física.

Castro, ALC (2003). Manual de Desastres: desastres naturais. Brasília: Imprensa Nacional.

CODECIPE. (2018). Situação dos Municípios. Acesso em 28 janeiro, em http://www.comunidades.pe.gov.br/c/portal/layout?p_1_id=PUB.1670.5.

CPTEC. (2018). Boletim Técnico. Acesso em 26 janeiro, em http://tempo.cptec.inpe.br/boletimtecnico/pt.

Duarte, CC, Nóbrega, RS \& Coutinho, RQ. (2015). Análise climatológica e dos eventos extremos de chuva no município do Ipojuca, Pernambuco. Revista de Geografia (UFPE), $32(2)$.

Hundecha, Y, Pahlow, M \& Schumann, A. (2009). Modeling of daily precipitation at multiple locations using a mixture of distributions to characterize the extremes. Water resources research, 45(12).

IBGE. (2019). Cidades e Estados. Acesso em 26 janeiro, em https://www.ibge.gov.br/cidades-e-estados/pe/bodoco.html. 
INMET. (2018). Dados Históricos. Acesso em 26 janeiro, em

www.inmet.gov.br/portal/index.php?r=bdmep/bdmep.

Kobiyama, M, Mendonça, M, Moreno, DA, Marcelino, IPVO, Marcelino, EV, Gonçalves, EF \& Rudorff, FDM. (2006). Prevenção de desastres naturais: conceitos básicos. Curitiba: Organic Trading.

Marengo, JA, Alves, LM, Beserra, EA \& Lacerda, FF. (2011). Variabilidade e mudanças climáticas no semiárido brasileiro. Recursos hídricos em regiões áridas e semiáridas, 1 . Recursos hídricos em regiões áridas e semiáridas. ISBN 978-85-64265-01-1. Instituto Nacional do Semiárido. Campina Grande - PB.

Marinha do Brasil. (2018). Cartas Sinóticas. Acesso em 28 janeiro, em https://www.marinha.mil.br/chm/dados-do-smm-cartas-sinoticas/cartas-sinoticas.

Medeiros, VS. (2013). Análise estatística de eventos críticos de precipitação relacionados a desastres naturais em diferentes regiões do Brasil (Doctoral dissertation, Universidade de São Paulo).

Mendonça, F \& Danni-Oliveira, IM. (2017). Climatologia: noções básicas e climas do Brasil. Oficina de textos.

MME. (2005). Projeto cadastro de fontes de abastecimento por água subterrânea, Pernambuco. Acesso em 26 janeiro, em http://rigeo.cprm.gov.br/xmlui/bitstream/handle/doc/15749/Rel_Bodocó.pdf?sequence=1 .

Molion, LCB \& Bernardo, SDO. (2002). Uma revisão da dinâmica das chuvas no nordeste brasileiro. Revista Brasileira de Meteorologia, 17(1), 1-10.

Monteiro, LR \& Kobiyama, M. (2014). Influências da distribuição temporal de precipitação no mapeamento de inundação. Revista de Gestão de Água da América Latina, 11(2), 25-35. 
Moura, MO, Cunico, C, Nóbrega, RS. \& Duarte, CC. (2016). Desastres hidrometeorológicos na região Nordeste do Brasil: distribuição espaço-temporal dos reconhecimentos de Estado de Calamidade Pública. Caderno de Geografia, 26(2), 259-271.

Nobre, P \& Melo, AD. (2001). Variabilidade climática intrasazonal sobre o Nordeste do Brasil em 1998-2000. Revista Climanálise, ano, 2.

Nóbrega, RS, Farias, RFDL \& Santos, CACD. (2015). Variabilidade temporal e espacial da precipitação pluviométrica em Pernambuco através de índices de extremos climáticos. Revista brasileira de meteorologia, 30(2), 171-180.

Olímpio, JLS. (2013). Desastres naturais associados à dinâmica climática no Estado do Ceará: subsídios à gestão dos riscos de secas e de inundações. Fortaleza: UFC. (Doctoral dissertation, Dissertação de Mestrado-Programa de Pós-Graduação em Geografia, Universidade Federal do Ceará, Fortaleza).

Ometto, JC. 1981, Bioclimatologia Vegetal. Editora agronómica Ceres Ltda. São Paulo, 425.

Pereira, AS, Shitsuka, DM, Parreira, FJ \& Shitsuka, R. (2018). Metodologia da pesquisa científica. [e-book]. Santa Maria. Ed. UAB/NTE/UFSM. Disponível em: https://repositorio.ufsm.br/bitstream/handle/1/15824/Lic_Computacao_MetodologiaPesquisa Cientifica.pdf?sequence $=1$.

Prefeitura de Bodocó. (2018). Prefeito de Bodocó decreta Estado de Situação de Emergência após fortes chuvas. Acesso em 28 janeiro, em https://bodoco.pe.gov.br/prefeito-de-bodocodecreta-estado-de-situacao-de-emergencia-apos-fortes-chuvas/.

Sá, IIS., Galvincio, JD, Moura, MSB \& Sá, IB. (2010). Cobertura vegetal e uso da terra na Região Araripe Pernambucana (analysis of vegetable cover and land use in the Araripe Pernambuco). Mercator, 9(19), 143-a.

Souza, WM, Azevedo, PV \& de Araújo, LE. (2012). Classificação da precipitação diária e impactos decorrentes dos desastres associados às chuvas na cidade do Recife-PE. Revista Brasileira de Geografia Física, 5(2), 250-268. 
Souza, WM, Azevedo, PV, Assis, JMDO \& Sobral, MDCM. (2014). Áreas de risco mais vulneráveis aos desastres decorrentes das chuvas em Recife-PE. Revista Brasileira de Ciências Ambientais (Online), (34): 79-94.

Steinke, ET, Souza Rezende, M \& Cavalcanti, L. (2006). Sistemas atmosféricos geradores de eventos extremos de precipitação em outubro de 2006 no Distrito Federal: uma análise geográfica dos desastres. Revista Brasileira de Climatologia, 2.

Tundisi, JG. (2003). Ciclo hidrológico e gerenciamento integrado. Ciên e Cult., 55(4): 31-3.

\section{Porcentagem de contribuição de cada autor no manuscrito}

Maria Fernanda da Cruz Silva - 40\%

Eliezio Nascimento Barboza - 30\%

Ana Millene dos Santos Silva - 30\% 